\title{
LA RETÓRICA ARGUMENTATIVA DE FRAY MARTÍN DE VELASCO (COLOMBIA, SIGLO XVII)
}

Mauricio BEUCHOT

UNAM, México

La retórica era puesta por los escolásticos dentro del campo de la lógica, junto con la dialéctica. Si se quiere, entraba en la lógica tomada en su expresión más amplia, como teoría de la argumentación. Los escolásticos tenían una teoría de la argumentación en la que se conjugaban la lógica analítica, o de la verdad necesaria, la lógica dialéctica (en el sentido de «tópica»), o de la verdad sólo probable, y la retórica, $\mathrm{o}$ de lo meramente verosímil. ( $\mathrm{Y}$ aun incluían la poética, como la que hacía creíble, verosímil o aceptable una composición literaria.) En seguida veremos un ejemplo de esta concepción de la retórica como parte de la teoría de la argumentación. Ciertamente la disciplina oratoria sufrió épocas de descrédito, porque se la tomaba como puramente emotiva y engañosa; pero en los escolásticos no era así. Era un arte argumentativa que aludía a todo el hombre (emoción y razón) y se dirigía a él tomándolo como ubicado dentro de un público concreto.

El Arte de sermones de fray Martín de Velasco es una obra de retórica eclesiástica impresa dos veces en México y usada para la enseñanza y formación de los predicadores noveles. De su autor sabemos que fue un franciscano de Santa Fe de Bogotá, del reino

Endoxa: Series Filosóficas, $n^{\circ} 6,1995$, UNED, Madrid:

Mauricio Beuchot: La retórica argumentativa de Fray Martín de Velasco (Colombia s. xoii). pp. 167-179. 
de Granada en las Indias, o de la Nueva Granada, i.e. la actual Colombia, nacido hacia $1621^{1}$. Fue además nombrado custodio y padre perpetuo de la provincia franciscana de ese lugar. Su obra conoció alguna fama, tanto en España como en la América Hispana, en Colombia y en México. El ejemplar de la obra que tenemos es una reimpresión de 1728.

Lo que nos ha parecido importante para la historia de la Nueva España es que esa obra fue estudiada por los que en ella se preparaban par el oficio de la predicación, y porque tuvo en México alguna fortuna, pues corría en copia manuscrita en antologías como la de fr. José Jiménez ${ }^{2}$ y además fue impresa en las prensas novohispanas por lo menos dos veces. No sólo era utilizada por los de su orden, los franciscanos, sino por otros como los diocesanos, pues la reimpresión de 1728 fue hacha a costa del bachiller Gabriel de Rivas, presbítero domiciliario del arzobispado de México, esto es, por un clérigo secular. $Y$ es que en verdad era un buen compendio de retórica para uso de los eclesiásticos, y se ve que como tal fue muy apreciado ${ }^{3}$.

La obra se inicia con una apasionada dedicatoria a San Antonio de Padua, gran predicador de la orden franciscana. Trae en seguida una aprobación del Dr. Pedro Ramírez del Castillo, catedrático de elocuencia y filosofía en el Colegio Real y Seminario Metropolitano. Viene además un parecer de fr. José López, lector

${ }^{1}$ El mismo dice en el Prólogo que al entregar a las prensas su libro tenía 56 años de edad. Por otra parte, en una de las Censuras del libro, la de fray José López, O.F.M., se dice que la primera edición del mismo fue en 1677. Si ambas cosas son ciertas, el autor debió nacer en la fecha que mencionamos.

${ }^{2}$ J. Jiménez, O.F.M., Rhetorica cristiana ad concionandi et orandi vsum accommodata..., Sin lugar, 1703. después de la Rhetorica christiana de Jiménez, contiene manuscrita la obra de Velasco, con el título Arte práctica e industrial para facilitar al nuevo predicador en el uso de las partes de la retórica; ver J. Yhmoff Cabrera, catálogo de obras manuscritas en latín de la Biblioteca Nacional de México, México: UNAM, 1975, p. 198. núm. 282.

${ }^{3}$ En su mismo Parecer o Censura nos dice fray José López que el libro había sido conocido en "uno y otro reino", ya con cuatro aprobaciones (es decir, cuatro ediciones por lo menos) desde 1677 en que se publicó por primera vez. Encomia además la fama bien ganada del autor y su probada competencia en cuestiones tanto de retórica como de teología. 
de prima de teología en el Convento de San Francisco de México. Tiene, asimismo, las licencias del Gobierno civil y del eclesiástico.

Avanzando un poco más, topamos con un prólogo al lector, en el que el autor explica por qué publica el Arte, a pesar de haber muchos, y qué intenta. Lo publica - dice- porque ve en los otros tantos defectos, que parecen darle licencia para que imprima el suyo. Lo que quiere hacer, sobre todo, es compendiar lo útil y rechazar lo recargado y grandilocuente. Busca la sencillez, y quiere reducir las partes del sermón a sus lugares apropiados. Establece: "La Rectorica enseña, que todas sus obras se hagan con fundamento: $y$ en este caso, debiendo ser ingeniero el entendimiento, por no dispertarle al trabajo, le damos música con una descripción de pájaros, y mariposas» (p. 13). Aclara que el arte no da ingenio, sino agudeza, y aun ayuda al ingenio con el ejercicio. $Y$ añade con orgullo que es un libro escrito en las Indias, a pesar de que los comuneros de España no quieran creer que en las Indias puede haber ingenios.

El Arte de sermones expone la materia en 29 capítulos o incisos. Velasco empieza definiendo el sermón como «un todo artificioso, que la Rectorica Christiana dispone, para persuadir a las virtudes, y aborrecimiento a los vicios; pena, y gloria con brevedad de palabras» (p. 19). Es un todo artificioso, porque resulta como producto de la técnica o arte retórica. Su fin es persuadir de que se viva virtuosamente y se abandonen los vicios, ya que la retórica sirve eminentemente para utilizarse en cuanto a las cosas prácticas, ya de la moral, de la religión, de la política o del derecho, pues son cosas contingentes, no necesarias, y muy sujetas a la discusión, no evidentes. Si fueran evidentes, no requerirían de persuasión. $O$, si son evidentes, como las normas de la moral cristiana para los creyentes, falta hacer evidente la necesidad de cumplirlas y además mover la voluntad para que las cumpla de verdad en la vida diaria. Así, la retórica convence y persuade. Convence por la argumentación, y persuade por la seducción del ornato literario; es al mismo tiempo una aplicación de la lógica y de la literatura (al menos como preceptiva literaria). 
De la misma manera, la retórica sagrada, fielmente reflejada en este Arte de hacer sermones, estaba orientada a provocar la acción moral, esto es, mover a una vida conforme a las virtudes y las leyes cristianas. Quería llevar a la práctica del bien y de la caridad. Ya la retórica en sí misma es eminentemente el instrumento «lógico» de la moral ${ }^{4}$, pues no siempre son claras y evidentes para todos las normas morales que se proponen; $y$, aun cuando lo sean, como en el caso de los adeptos de una escuela filosófica o de los fieles de una religión, no hay clara inclinación a cumplirlas, debido a la debilidad y a la miseria moral del hombre. En el caso de los cristianos, para mover a los cuales servía el Arte de hacer sermones, había claridad en cuanto a la norma, pero no había motivación para cumplirla; el predicador tenía que levantar los ánimos y encender los corazones para lograrlo. Pero no era asunto sólo de la voluntad; nada se ama si no se conoce; por ello también había que dirigirse a la inteligencia. En ese sentido la retórica cristiana era argumentación y psicagogía, como ya había enseñado Aristóteles y se había repetido en la Edad Media ${ }^{5}$.

Efectivamente, esto lo había ya señalado Aristóteles en su Metaphysica, y lo había reglamentado en su Rhetorica. La retórica, decía el Estagirita, tiene aplicación sobre todo a las cosas de la práctica, como lo hemos dicho; pero también se podría aplicar a las cosas teóricas. Puede incluso, además de aplicarse a las cosas discutibles, a las cosas de suyo evidentes, pero de alguien, por ofuscamiento, no quiere aceptar. La lógica versa sólo sobre las cosas evidentes y necesarias, pero no sobre las contingentes y

\footnotetext{
4Ver V. Camps, Etica, retórica, política, Madrid: Alianza, 1988, pp.37 y 41.

${ }^{5}$ Ver J. J. Murphy, Rhetorics in the Middle Ages. A History of Rhetorical Theory from Saint Augustine to the Renaissance, Berkeley - Los Angeles-London: University of California Press, 1974, pp. 269 ss. Ver también M. Beuchot y E. González Ruiz, «La retórica profética de San Vicente Ferrer», en Ensayos (UAM, México, n. 11 (1986), pp. 1-16; los mismos, "San Vicente Ferrer: técnica retórica y actitud profética», en Teología Espiritual (valencia, España), 31, (1987), pp. 121139.
} 
discutibles; en cambio, la dialéctica o tópica y la retórica sí pueden aplicarse tanto a lo suyo como a lo de la lógica ${ }^{6}$.

En efecto, aunque las cosas contingentes y opinables no son susceptibles de una demostración necesaria y apodíctica, de las cosas necesarias y evidentes sí se puede dar una argumentación probable o verosímil; por ejemplo, al que no acepta el principio de no contradicción, no hay manera de demostrárselo apodícticamente; o bien -como decía Aristóteles- - se le considera enajenado, o bien se le argumenta solamente de manera indirecta, persuasiva, de una manera retórica en el fondo. Cuando nuestro interlocutor nos niega las cosas que son principios, no hay otra forma de argumentar con él; por ello, a ese nivel tan fundamental, la argumentación es retórica; mucho más la argumentación religiosa ${ }^{7}$.

Ya que el Arte nos ha definido el sermón como un todo, nos lo divide en sus distintas partes, unas esenciales, otras integrales y otras materiales. Las partes esenciales son sus diversas funciones: enseñar, deleitar y mover. Enseñar se hace por la argumentación; el deleitar y el mover se logran por el ornato y la persuasión. Incluso se nos dice que la retórica sacra reúne en el sermón las tres funciones, pues mira a «enseñar, deleitar, y persuadir a los oyentes» (p. 21). Enseña y persuade, es decir, alude a la razón y al corazón. $Y$ es que la retórica tiene como ideal añadir al discurso del intelecto el discurso de los sentimientos. Pascal, en desgarradora lucha con su propio racionalismo de origen, quiso separar ambos discursos, y hablaba de las razones de la inteligencia y de «las otras razones» (las del corazón); pero la tradición retórica griega y escolástica quiere, al contrario, conjuntarlas. Pascal hablaba, por una parte, del espíritu geométrico, racionalista y demostrativo, y, por otra, del espíritu de fineza, cordial y emotivo; y no parecían poder reunirse. Llegó a decir que sólo Dios podía

\footnotetext{
"Ver M. Beuchot, "Retórica, dialéctica y filosofía en Boecio», en Investigación Humanística (UAM, México), 3/2 (1986), pp. 73-85.

${ }^{7}$ Ver M. Beuchot, "Algunos aspectos de la retórica en Fray Luis de Granada», en la Ciencia Tomista (Salamanca, España), 113 (1986), pp. 127-143.

${ }^{8}$ Ver C. Pereda, «Las otras razones», en Theoría (UNAM, México), 1 (1980).
} 
comprender el corazón del hombre, porque El lo había creado; y a nosotros sólo nos quedaba dirigirnos a la razón, convencerla y persuadirla. Por ello la retórica tenía que ser prácticamente sólo racional: la mejor pieza de oratoria serían los Elementos de Euclides 9 . Ya que el corazón del hombre era tan descontentadizo, no quedaba más que argumentar para la razón. En ese sentido, el formalismo lógico o matemático sería el mejor para argumentar, para convencer y persuadir. De acuerdo con ello, la labor de la retórica era dirigirse a la razón con términos claros o bien definidos, y con enunciados de verdad evidente o bien comprobada. Pero sabemos que eso no siempre se puede hacer; más aún, sabemos que, a pesar de que algunas veces se pudiera, no sería suficiente. La claridad y la sencillez no bastan. El contexto racionalista de Pascal le hacía buscar lo claro y lo distinto (del ideal epistemológico cartesiano) donde no puede hallarse. Muchas cosas de la vida cotidiana, de la vida moral, religiosa, jurídica o política, escapan a lo claro y lo distinto, y no se manifiestan con una verdad evidente dentro de un raciocinio contundente; no se pueden reducir a la claridad y la distinción. Si pudieran hacerlo, no serían tan discutibles ni necesitarían persuasión para ser aceptadas. Pues bien, la retórica se refiere a esas cosas no claras ni evidentes, tanto de la teoría como de la práctica, que hay que mover a creer o a hacer. Por ejemplo, la retórica sacra usaba el sermón para motivar a la aceptación de la ley de Dios y para mover a la acción moral buena, o dejar la vida de pecado y abrazar la virtud.

Por eso la oratoria sagrada tiene como fin y cometido enseñar, deleitar y mover, las cuales son sus partes esenciales. Sus partes integrales - según nos sigue diciendo el Arte de hacer sermonesson la invención, la elección, la disposición y la pronunciación; porque en el sermón se necesita «inventar qué, y cómo de lo inventado elegir, lo mejor y lo más a propósito. $Y$ de lo elegido,

9 Ver M. Beuchot, «Introducción» a Blas Pascal, «Del espíritu geométrico y del arte de persuadir", en Tetraktys (UIA, México), n. 3 (1987), pp. 3-8. 
disponer en sus lugares. $Y$ lo así dispuesto: escribirlo, decirlo, y predicarlo» (p. 21). Y las partes materiales del sermón son la introducción, el orden dentro de los discursos, de modo que se sucedan convenientemente, $y$, dentro de los discursos, el orden y lugar de los conceptos (cfr. p. 22). Todo ello se ordena y dispone con el arte retórica, que da la forma a esa materia, que estructura esos contenidos, de acuerdo con el público al que va dirigido el sermón o discurso.

Y es que, en efecto, la retórica busca la adhesión de los oyentes, y ésta se da según grados, no de manera uniforme. Ya en ello aparece la noción de auditorio, tan puesta de relieve recientemente por Chaim Perelman en la teoría de la argumentación llamada «nueva retórica». La idea es que los argumentos, en lugar de ser como el «calculemus» de Leibniz, en el vacío, se dan siempre en relación con un auditorio. No se trata de establecer un relativismo de la argumentación ni de la lógica, pues las cosas necesarias y deductivas no son relativas, sino absolutas; pero la cosas contingentes y discutibles sí lo son. Y son la mayoría. Ellas suponen una audiencia, un público. Incluso la reflexión solitaria puede imaginarse como teniendo a uno mismo por auditorio; mucho más cuando se escribe un artículo o se dicta una conferencia. Por lo demás, un juzgado y un templo tienen un auditorio específico. No se dan en abstracto, sino en concreto. $Y$, si se dirige a un auditorio concreto, el orador tiene que adaptarse a él. Incluso se puede suponer la idea de un "auditorio universal», pero será un ente ideal, que siempre estará recibiendo restricciones y adaptaciones al auditorio concreto. Tal vez sólo en filosofía pueda uno dirigirse a un auditorio universal, de los seres humanos razonables; pero basta un desacuerdo en alguno de los principios, para que se acabe frente a un auditorio específico o particular. No se niega el auditorio universal, pues la razón es universal; pero encuentra algunas diferencias de funcionamiento concreto en los diversos grupos políticos, escuelas filosóficas o iglesias religiosas.

El mismo Perelman dice: «Lo que conservamos de la retórica tradicional es la idea de auditorio, que es evocada inmediatamente 
cuando se piensa en un discurso. Todo discurso se dirige a un auditorio; $y$, demasiado frecuentemente, se olvida que esto mismo sucede con cualquier escrito. Mientras que el discurso se concibe en función del auditorio, en cambio, la ausencia material de los lectores puede hacer creer al escritor que está solo en el mundo, aunque, de hecho, su texto se encuentre siempre condicionado, conscientemente o no, por aquellos a los cuales pretende dirigirse» ${ }^{10}$. Pero la noción de discurso se aplica tanto a la pieza hablada como al texto escrito (y a otros, como los gestos, las acciones, etc., que también son textos) ${ }^{11}$.

En la exposición de Velasco sigue la aplicación del primer artificio, o primera forma fundamental que organiza las partes materiales, y es el orden de ciencia. Este consiste en aplicar la lógica a los sermones, pues la lógica tenía - para estos pensadores escolásticos-como objetivo principal los tres modos de saber, que son: definir, dividir y argumentar. La definición se hace en la narración del asunto, hipótesis o argumento, donde se propone y delimita el tema. La división se propone también en la introducción del sermón (Velasco dice que de preferencia en tres partes).

\footnotetext{
${ }^{10} \mathrm{Ch}$. Perelman - L. Olbrechts-Tyteca, "La nueva retórica» (1956), en Ch. Perelman - L. Olbrechts-Tyteca - M. Dobrosielski, Retórica y lógica, México: UNAM, 1987 (2a. ed.), p. 417.

${ }^{11}$ La noción de auditorio universal es concebida por Perelman como una especie de oyente Kantiano ideal: «¿Qué hacer cuando el auditorio al cual uno se dirige no es ni especializado ni limitado; cuando, por un discurso no ad hominem, sino ad humanitatem, uno se dirige a toda la humanidad razonable, como es el caso de los filósofos? (...) Semejante argumentación, que se podría calificar de racional, se conformará al imperativo categórico de Kant: no debo admitir ni proponer a otro más que "construcciones intelectuales que puedan valer al mismo tiempo y siempre con respecto a una universalidad de los espíritus» (Ch. Perelman, "La nouvelle rhétorique comme théorie philosophique de l'argumentation", en Memorias del XIII Congreso Internacional de Filosofía, México: UNAM, 1964, vol. V, pp. 269-270). Es un intento de no relativizar completamente la argumentación respecto del auditorio, sino de darle un carácter lo menos relativista y lo más universal que se pueda. Es un cierto principio de universalización. Sin embargo, el mismo Perelman reconoce que puede haber concepciones diversas de lo que es este auditorio universal, es decir, que se puede entender de diversas maneras qué cosa es tal auditorio universal, supuestamente el hombre razonable (ver el mismo «Rhétorique et philosophie» (1969), en el mismo, Le Champ de l'argumentation, Bruxelles: Presses Universitaires de Bruxelles, 1970, pp. 225-226).
} 
La argumentación consiste en ponerse dificultades y deshacerlas con agudeza; esto ha de hacerse en todo sermón, procurando que se vea la transición e inferencia de unos conceptos y proposiciones a otros. Pero sobre todo debe lograrse en la parte de las pruebas (después del tercer discurso o tercer apartado), para culminar en la conclusión reducción, peroración o epílogo (p. 36). Las pruebas, en el caso del sermón, son argumentos de razón y, sobre todo, de autoridad. No que se trate de un uso exclusivo del argumento de autoridad, pero sí privilegiado; pues, como dice Perelman, la argumentación retórica, que se da en relación a un auditorio, tiene que valerse de las opiniones y los valores a los que más se adhiere éste, y en el caso de sermón, que se dirige a un público religioso, tendrá que echarse mano a las Sagradas Escrituras y a los santos o teólogos más autorizados. Más aún, el propio Perelman llega a decir que el discurso teológico, a diferencia de otros, «se dirige sólo a los creyentes que admiten desde el comienzo ciertos dogmas o ciertos textos sagrados» ${ }^{12}$. Esos son los lugares comunes de ese contexto, es decir, valores comunes, nociones comunes y directivas comunes, puestas en lenguaje común, a todos esos oyentes. Ya que esos oyentes los han aceptado, ir en contra de ello sería contradecirse; y eso constituye un buen argumentum ad hominem no sofístico, sino válido, que hace razonable la argumentación ${ }^{13}$.

Velasco añade en su Arte de sermones la explicación de las partes integrales, que son la invención, la elección, la disposición y la pronunciación. Dice que el sermón no sólo debe llevar el orden de la ciencia, o argumentativo, sino también el más propiamente retórico, que es el del ornato. Así llega a la materia la forma de exornación (p. 40). Como la invención tiene su lugar más propio en la introducción, se detiene a enseñar cómo hacer buenas introducciones o exordios. En cambio, la elección de materiales y

\footnotetext{
${ }^{12} \mathrm{Ch}$. Perelman, «Rhétorique et philosophie», ya citado, p. 226.

${ }^{13}$ En el campo de la filosofía, esta aplicación del argumento ad hominem como peculiar a todas las polémicas filosóficas ha sido estudiado por H.W. Johnstone, Jr., "Philosophy and Argumentum ad Hominem», en Journal of Philosophy, 49 (1952), pp. 489-498.
} 
la disposición de los mismos pervade todo el sermón, no en un solo lugar, sino en todos. Y lo mismo la pronunciación, gesto, elocución o elocuencia, a la que el autor da un lugar aparte.

Podrá decirse que la retórica no admite diálogo y que por tanto es una argumentación monológica. Sobre todo en la oratoria sagrada, en la que sólo habla el predicador desde el púlpito, proponiendo su sermón $\mathrm{u}$ homilía a unos oyentes que permanecen pasivos. Pero hay por lo menos un cuasidiálogo, pues Velasco pide que la argumentación se haga sobre todo proponiéndose dificultades el propio predicador, es decir, debe preguntarse las cuestiones que se plantean los oyentes, debe anticiparse a sus objeciones y responderlas, debe convencerlos de su interpretación de las escrituras o exégesis bíblica. En esa necesidad de abogar por su interpretación, se parece la hermenéutica a la retórica ${ }^{14}$.

La elocuencia versa sobre el estilo de pronunciar los sermones. Dicho estilo es «natural, pulido, con arte, propio, significativo y lleno de sentencias» (p. 46). Se divide en tres especies: estilo remiso o sumiso, blando o templado, y magnílocuo o grandílocuo. Estudiar los estilos sirve para dar variedad de tonos al sermón, de modo apropiado, y para evitar monotonías y exageraciones. Con todo, Velasco insiste en que hay que dar preferencia a la razón, aunque tropiece el estilo. Por otra parte, el estilo debe ser apropiado a la audiencia. Se dan algunos consejos para usar unos u otros según el sermón o la parte suya de que se trate. De acuerdo con ello, la elocuencia (sobre todo la cristiana) es saber gobernar bien y con propiedad los tres géneros de estilo (p. 75). La forma de exornación culmina con el buen manejo del gesto o semblante, además de la pronunciación. Velasco define, con Casiodoro, el gesto o semblante como «un silencio elocuente» (p. 86). Para ello se analizan los gestos que convienen a cada estilo.

Después de la forma artificial de la exornación, viene la forma substancial del provecho, según cada una de las partes esenciales

\footnotetext{
14 Ver M. Beuchot, «Hermenéutica y retórica en Hans Georg Gadamer», en Semiosis (Xalapa, ver.), 18 (1987), pp. 141-148.
} 
(enseñanza, deleite y motivación) sobre las materiales. Así, se habla de los modos y estilos apropiados para enseñar, para deleitar y para mover los ánimos. Velasco tiene el mérito de combatir a los que exageran y pervierten los estilos. Insiste en que hay que enseñar sin un estilo árido, deleitar sin un estilo afectado, y mover o persuadir sin un estilo exacerbado. Para todo ello desarrolla el arte de los conceptos, el arte de las proposiciones y el arte de los discursos, así como el arte de enseñar, el arte de deleitar y el arte de persuadir con reglas y consejos que ayudan a lograr bien estas cosas. Y pone ejemplos de todo ello. Velasco termina haciendo la "reducción» $o$ análisis de las partes principales de la retórica que ha expuesto. Son tres artificios los que hacen este arte: el primer artificio es el orden de la ciencia, que da la forma fundamental al sermón; el segundo es el orden de la retórica, que da la forma de exornación; el tercero es el orden de la misma retórica aportando la forma de provecho; estas formas organizan las partes materiales del sermón (introducción y discursos). En las partes integrales (invención, elección, disposición y elocuencia) la organización viene dada por los estilos que convienen a cada parte, según los conceptos, las proporciones y los discursos que se elaboran. $Y$ en las partes esenciales (enseñar, deleitar y mover) la retórica efectuó la organización, «dando nuevo espíritu a las introducciones con la enseñanza, y magisterio, a los finales con la persuasión, y a la armonía de toda la obra con el deleite» (p. 227). Con eso ya al predicador sólo le resta -dice Velasco - implorar del cielo la inspiración, y ya está todo.

Según lo que hemos dicho, la retórica - a veces tan desacreditada por los excesos que parecen indicar lo contrario- se inscribe en una concepción de la lógica más amplia que la sola lógica formal, impregna lo que en la actualidad se llama a veces «teoría de la argumentación», que también es la «lógica informal». Implica, pues, que el campo de la lógica no se agota en lo apodícticamente demostrable. Ya de suyo la lógica tópica (o dialéctica en el sentido de Aristóteles) ampliaba ese campo a lo opinable, es decir, quería hacer ver que la lógica no sólo se aplica a lo necesario, sino 
también a lo contingente. $Y$ no sólo a lo que se pueda conocer como verdadero, sino además a lo que únicamente alcanza a conocerse como verosímil. Se trata, pues, de ampliar lo más posible el ámbito de la lógica, para que no renuncie a cosas que quedarían fuera de la racionalidad, i.e. de lo racional y lo razonable. Hay cosas que no se pueden demostrar apodícticamente, pero que pueden argumentarse, razonarse. La retórica se ocupa de las cosas más difíciles de someter a la razón, a saber, los hechos contingentes y las cosas prácticas, que sólo aspiran a brindar de ellos un conocimiento verosímil. Por ejemplo, lo que no se discute en un tratado de lógica, de matemática, ni en uno de física, ni siquiera de lo que se trata en cosas comunes y aceptadas en la filosofía teórica, sino en los terrenos más movedizos, como en las ciencias sociales y en la misma filosofía en su parte moral, o en los juzgados, o en la tribuna política, o en el púlpito, etc. Todo eso es susceptible de ser tratado no únicamente a base de puros sentimientos y emociones, o por la manipulación propagandística, sino -en el pensamiento de estos filósofos y teólogos de la Colonia, como Martín de Velasco- por la razón, pero conducida de manera más amplia que la que se aplica en las disciplinas deductivas; es decir, como se aplica en los casos -que son los más- en los que no se puede hacer una inferencia deductiva, por no contar con el convencimiento de los demás, y hay que lograrlo. Esta idea antigua $y$ tradicional (grecorromana y cristiana) ha recibido impulso en la reciente teoría de la argumentación (p. ej. con Toulmin y Johnstone), en la lógica informal (con Walton y Woods) y en la «nueva retórica» (Perelman). Ellos participan del ideal retórico de pensadores escolásticos del tiempo colonial, como Martín de Velasco, cuyo Arte retórico para hacer sermones hemos hablado.

El ideal de la retórica - antes como ahora-por lo tanto, es dar cabida a la razón en las cosas humanas; no es, como a causa de un racionalismo extremo se ha creído, algo irracional y puramente emotivo, cual si fuera una especie de engaño emocional, control y manipulación de los sentimientos. No. La retórica ha querido ser 
una apuesta a favor de la razón, pero de una racionalidad que impregna diversamente (en distintas medidas, pero sin llegar a diluirse ni a trivializarse) las cosas que ilumina. No hay la misma medida de racionalidad en una prueba geométrica que en un juzgado, o en un parlamento, o en un púlpito, o en el debate filosófico acerca de los principios últimos - ni puede exigirse la misma-. En esos otros casos, que son los más, sólo se puede pedir lo que Perelman llama «lo razonable». pero es la razón, y es la lógica, al fin y al cabo. $Y$ esto fue lo que quiso hacer el colombiano fray Martín de Velasco en su compendio de retórica, muy usado en el tiempo colonial mexicano. 